\title{
Front Matter: Volume 8199
}

, "Front Matter: Volume 8199," Proc. SPIE 8199, 2011 International Conference on Optical Instruments and Technology: Optical Sensors and Applications, 819901 (6 November 2011); doi: 10.1117/12.921659

SDIE Event: International Conference on Optical Instruments and Technology (OIT2011), 2011, Beijing, Beijing, China 


\title{
PROCEEDINGS OF SPIE
}

\section{International Conference on Optical Instruments and Technology Optical Sensors and Applications}

\author{
Brian Culshaw \\ YanBiao Liao \\ Anbo Wang \\ Xiaoyi Bao \\ Xudong Fan \\ Editors
}

6-9 November 2011

Beijing, China

Sponsored by

CIS - China Instrument and Control Society

COS - The Chinese Optical Society

SPIE

Cooperating Organizations

Opto-Electronic - Mechanic Technology and System Integration Chapter, CIS (China) • Beijing Institute of Technology (China) - University of Shanghai for Science and Technology (China) Capital Normal University (China) - Optical Instrument Chapter, CIS (China) • Committee on Optoelectronic Technology, COS (China) • Beijing Hamamatsu Photon Techniques Inc. (China) Tianjin University (China) • Zhejiang University (China) • Tsinghua University (China) • Chongqing University (China) • Nanjing University (China) • Instrument Society of America (China) • Institute of Measurement and Control (United Kingdom) • Hong Kong Institution of Engineers (China) • The Society of Measurement and Control (Japan)

Published by

SPIE

Volume 8199 
The papers included in this volume were part of the technical conference cited on the cover and title page. Papers were selected and subject to review by the editors and conference program committee. Some conference presentations may not be available for publication. The papers published in these proceedings reflect the work and thoughts of the authors and are published herein as submitted. The publisher is not responsible for the validity of the information or for any outcomes resulting from reliance thereon.

Please use the following format to cite material from this book:

Author(s), "Title of Paper," in 2011 International Conference on Optical Instruments and Technology: Optical Sensors and Applications, edited by Brian Culshaw, YanBiao Liao, Anbo Wang, Xiaoyi Bao, Xudong Fan, Proceedings of SPIE Vol. 8199 (SPIE, Bellingham, WA, 2011) Article CID Number.

ISSN 0277-786X

ISBN 9780819488404

Published by

SPIE

P.O. Box 10, Bellingham, Washington 98227-0010 USA

Telephone +1 3606763290 (Pacific Time) · Fax +1 3606471445

SPIE.org

Copyright (C) 2011, Society of Photo-Optical Instrumentation Engineers

Copying of material in this book for internal or personal use, or for the internal or personal use of specific clients, beyond the fair use provisions granted by the U.S. Copyright Law is authorized by SPIE subject to payment of copying fees. The Transactional Reporting Service base fee for this volume is $\$ 18.00$ per article (or portion thereof), which should be paid directly to the Copyright Clearance Center (CCC), 222 Rosewood Drive, Danvers, MA 01923. Payment may also be made electronically through CCC Online at copyright.com. Other copying for republication, resale, advertising or promotion, or any form of systematic or multiple reproduction of any material in this book is prohibited except with permission in writing from the publisher. The CCC fee code is $0277-786 \mathrm{X} / 11 / \$ 18.00$.

Printed in the United States of America.

Publication of record for individual papers is online in the SPIE Digital Library.

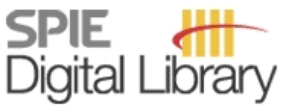

SPIEDigitalLibrary.org

Paper Numbering: Proceedings of SPIE follow an e-First publication model, with papers published first online and then in print and on CD-ROM. Papers are published as they are submitted and meet publication criteria. A unique, consistent, permanent citation identifier (CID) number is assigned to each article at the time of the first publication. Utilization of CIDs allows articles to be fully citable as soon as they are published online, and connects the same identifier to all online, print, and electronic versions of the publication. SPIE uses a six-digit CID article numbering system in which:

- The first four digits correspond to the SPIE volume number.

- The last two digits indicate publication order within the volume using a Base 36 numbering system employing both numerals and letters. These two-number sets start with $00,01,02,03,04$, $05,06,07,08,09,0 A, 0 B \ldots 0 Z$, followed by 10-1Z, 20-2Z, etc.

The CID number appears on each page of the manuscript. The complete citation is used on the first page, and an abbreviated version on subsequent pages. Numbers in the index correspond to the last two digits of the six-digit CID number. 


\title{
Contents
}

\author{
ix Symposium Committee \\ xi Conference Committee \\ xiii Introduction
}

\section{SESSION 1}

819902 A fibre optic oxygen sensor for monitoring of human breathing (Invited Paper) [8199-90] R. Chen, A. D. Farmery, Univ. of Oxford (United Kingdom); R. Chen, Univ. of Warwick (United Kingdom); C. E. W. Hahn, Univ. of Oxford (United Kingdom)

819903 In-line fiber Mach-Zehnder interferometer combining with fiber Bragg grating for simultaneous curvature and temperature measurement [8199-02]

$X$. Dong, China Jiliang Univ. (China); Y. Zhou, China Jiliang Univ. (China) and Zhejiang Province Institute of Metrology (China); W. Zhou, China Jiliang Univ. (China) and Nanyang Technological Univ. (Singapore); W. C. Wong, C. C. Chan, Nanyang Technological Univ. (Singapore); L.-Y. Shao, China Jiliang Univ. (China); J. Cheng, Zhejiang Province Institute of Metrology (China)

819904 Single crystal-based optical current sensor with electrically adjustable sensitivity [8199-71] C. Li, Beihang Univ. (China)

\section{SESSION 2}

819905 Coherence-collapse characteristics of single-mode DFB fiber laser sensors with external optical feedback (Invited Paper) [8199-22]

W. Liu, L. Ma, H. Yang, National Univ. of Defense Technology (China)

819906 A novel optical fiber reflective read out microcantilever biosensor [8199-40] F. Wen, Beijing Institute of Technology (China) and North Univ. of China (China); Y. Zhao, Beijing Institute of Technology (China); X. Yu, Peking Univ. (China)

819907 Ni-P coating metallization on fiber Bragg grating without fiber coarsening and its temperature sensing property [8199-42]

A. Q. Tang, L. Fang, S. J. Xue, B. Yin, L. Liu, P. Zhang, Chongqing Univ. (China)

819908 Numerical investigation of steam quality sensor based on wavelength modulated surface plasmon resonance [8199-10]

X. Li, C. Wang, Soochow Univ. (China)

$819909 \quad$ FPGA based filter design for self-mixing interferometry signals [8199-67]

Y. Sun, Y. YU, Univ. of Wollongong (Australia); W. Fan, Zhengzhou Univ. (China); J. Xi, Univ. of Wollongong (Australia) 
8199 OB Research on alignment method of the polarization coupling testing system [8199-43]

L. Yang, Z. Yang, J. Yang, L. Yuan, Harbin Engineering Univ. (China)

8199 0C The study of dispersion compensation in Optical Coherence Domain Polarization technology [8199-97]

Z. Yang, L. Yang, J. Yang, L. Yuan, Harbin Engineering Univ. (China)

8199 OD Optical fiber evanesent field sensors without additional functionalized material [8199-46]

X. Zhang, Z. Deng, H. XU, H. XU, J. Feng, South China Univ. of Technology (China)

\section{SESSION 4}

8199 OF Calibration technology for a polarization maintaining fiber temperature sensor (Invited Paper) [8199-88]

Y. Yang, L. Gao, W. Duan, BeiHang Univ. (China)

8199 OG Single-mode fiber sensor based on core-offset splicing [8199-36]

M. Zhou, S. Zhen, F. Liu, J. Peng, Beijing Institute of Micro Technology (China); L. Li, L. Lu, B. Yu, Anhui Univ. (China)

$8199 \mathrm{OH}$ The micro-vibration amplitude measuring method with suppressing peak-to-peak drift in PGC demodulation algorithm [8199-37]

F. Liu, Anhui Univ. (China); S. Zhen, Beijing Micro-Technology Research Institute (China); M. Zhou, G. Zhang, L. Lv, Anhui Univ. (China); J. Peng, Beijing Micro-Technology Research Institute (China); B. Yu, Anhui Univ. (China)

8199 0l Study on optic-fiber temperature/concentration sensor with reflective structure [8199-05] S. Yang, X. Wei, Beijing Glass Research Institute (China)

\section{SESSION 5}

8199 0J Optimization of a fiber optic flexible disk microphone (Invited Paper) [8199-38] G. Zhang, B. YU, H. Wang, F. Liu, Anhui Univ. (China); J. Peng, Beijing Institute of Micro Technology (China); X. Wu, Anhui Univ. (China)

8199 OK Optical fiber based sensing system design for the health monitoring of multi-layered pavement structure [8199-28]

W. Liu, H. Wang, Z. Zhou, S. Li, Y. Ni, G. Wang, Dalian Univ. of Technology (China)

$8199 \mathrm{OL}$ The behavior of a novel raw material-encapsulated FBG sensor for pavement monitoring [8199-84]

H. Wang, W. Liu, Z. Zhou, S. Wang, Y. Li, Dalian Univ. of Technology (China)

8199 OM Study on laser diode self-mixing vibrometer with wide dynamic range [8199-31]

K. Zhang, J. Yang, L. Zhai, B. Yu, L. Lu, Anhui Univ. (China) 
8199 ON New realization method for noise suppression in fiber interferometer sensors [8199-35]

K. Yang, J. Zhu, H. Wang, H. Yin, L. Li, B. Yu, Anhui Univ. (China)

819900 Strain monitoring of drilling riser in deepwater based on fiber Bragg gratings [8199-56]

Y. Jiang, D. Yang, J. Wang, J. Xu, C. Qin, W. Liao, J. Zhao, H. Wang, Northwestern

Polytechnical Univ. (China); S. Jiang, CNOOC Research Ctr. (China)

\section{POSTER SESSION}

8199 OQ An improved PGC demodulation method to suppress the impact of laser intensity modulation [8199-04]

H. Zhang, M. Zhang, L. Wang, Y. Liao, Tsinghua Univ. (China); D. N. Wang, HongKong

Polytechnic Univ. (Hong Kong, China); Y. Zhu, China Oilfield Services Ltd. (China)

8199 OR The design of integrated demodulation system of optical fiber hydrophone array for oceanic oil exploration [8199-07]

K. Wang, Tianjin Univ. (China); Q. Shi, C. Tian, Tsinghua Univ. (China); F. Duan, Tianjin Univ. (China); M. Zhang, Y. Liao, Tsinghua Univ. (China); Y. Zhu, China Oilfield Services Ltd. (China)

8199 OS The development of solar ultraviolet observation [8199-08]

X.-N. Zhang, Xian Jiaotong Univ. (China) and Xianyang Normal Univ. (China); C.-M. Zhang,

Xian Jiaotong Univ. (China)

8199 OT Fiber-optic curvature sensor based on step-index multimode fiber [8199-09]

Y. Gong, Univ. of Electronic Science and Technology of China (China) and Chongqing Univ. of Technology (China); T. Zhao, Y.-J. Rao, Y. Wu, H.-J. Wu, Univ. of Electronic Science and Technology of China (China)

8199 OU Optical voltage transducer based on polarization maintaining two-mode photonic crystal fiber [8199-12]

X. Lu, W. Bi, Yanshan Univ. (China)

8199 OV Refractive index sensing characteristics of fiber Bragg grating in the polarization maintaining microstructured optical fiber [8199-16]

X. Guo, W. Bi, F. Liu, Yanshan Univ. (China)

8199 OW Optical fibre relative humidity sensor based on a hydrogel coated long period grating [8199-17]

X. Yu, Heilongjiang Univ. (China); L. Wang, Tsinghua Univ. (China); J. Zhang, Heilongjiang Univ. (China); M. Zhang, Tsinghua Univ. (China); S. Liu, Heilongjiang Univ. (China); Y. Liao, Tsinghua Univ. (China)

8199 0X High optical carrier-suppression characteristics of Brillouin/erbium fiber laser [8199-19] M. Chen, H. Zhou, Z. Meng, National Univ. of Defense Technology (China)

8199 OY Effects of the absorption coefficient on the refractive index of germanium in a fiber optic-semiconductor temperature sensor [8199-25]

L. Peng, L. Min, P. Zhong, Wuhan Univ. of Technology (China) 
$81990 Z$ Theory and experimental research of a Y-phase-modulator based optical fiber current sensor [8199-27]

C. Zhang, C. Wang, S. Chen, China Electric Power Research Institute (China)

819910 Optimization for metal bonding technology of optical fiber sensor [8199-32]

H. Liu, W. Chen, P. Zhang, J. Wun, L. Liu, Chongqing Univ. (China)

819911 Design and fabrication of embedded two elliptical cores hollow fiber [8199-39]

F. Tian, L. Yuan, Q. Dai, Z. Liu, Harbin Engineering Univ. (China)

819912 An in-fiber refractometer based on asymmetrical twin-core fiber [8199-47]

Y. Zhang, A. Zhou, G. Li, Q. XU, T. Zheng, Harbin Engineering Univ. (China)

819913 Endoscope two dimensional scanning fiber probe and the driving method [8199-50]

G. Li, H. Gao, A. Zhou, Z. Liu, Harbin Engineering Univ. (China)

819914 The outstanding influence of end-face-TIR on enhancing signal intensity of fiber-optic EW fluorescence sensor [8199-53]

C. Wang, H. Chen, China Jiliang Univ. (China); J. Ma, Quebec Univ. (Canada)

819915 Bending-induced sensing sensitivity in single-longitude-mode DBR fiber laser [8199-55] J. Luo, Central South Univ. of Forestry and Technology (China); B. Liu, H. Zhang, Nankai Univ. (China); Y. Kang, M. He, Central South Univ. of Forestry and Technology (China)

819916 Research on distributed temperature sensor (DTS) applied in underground tunnel [8199-57] C. Hu, J. Wang, Z. Zhang, C. Shen, Y. Jin, S. Jin, China Jiliang Univ. (China)

819917 An embedded strain sensor in anchor zone for bridge cable tension measurement based on FBG [8199-63]

L. Liu, W. Chen, P. Zhang, J. Wu, H. Liu, Chongqing Univ. (China)

819918 Ladder topology network based on white light fiber-optic Mach-Zehnder interferometer [8199-64]

S. Li, L. Yuan, F. Mokhtar, Harbin Engineering Univ. (China)

819919 Distributed condition monitoring techniques of optical fiber composite power cable in smart grid [8199-68]

Z. Sun, Y. Liu, C. Wang, T. Liu, Laser Institute of Shandong Academy of Sciences (China)

8199 1A A new noise suppression algorithm for optical fiber temperature surveillance of heavy oil thermal recovery well [8199-69]

J. Wang, J. Han, Y. Pan, Xinjiang Oilfield Co. (China); M. Zhang, Q. Zou, S. Xie, Tsinghua Univ. (China)

8199 1B Phase retrieval for general phase diversity Based on Zernike decomposition and SPGD [8199-70]

H. Yang, Y. Li, Huaihai Institute of Technology (China) 
8199 1C A new surface plasmon resonance system with the function transforming freely from wavelength to angle modulation and the primary application in real time detection of antibody-antigen interaction [8199-72]

L. Q. Yang, H. Y. Zhang, X. L. Wang, Technical Institute of Physics and Chemistry (China)

8199 1D Research on fiber optic gradient hydrophone based on two interferometers scheme [8199-73]

F. Wang, S. Xiong, H. Luo, National Univ. of Defence Technology (China)

$81991 \mathrm{E}$ Induced mode hopping phenomenon via resonant cavity disturbances in ultra-narrow linewidth erbium-doped fiber ring lasers [8199-75]

M. Ma, Z. Hu, P. Xu, Y. Hu, National Univ. of Defense Technology (China)

8199 IF An optimized design of a fiber optic hydrophone based on side-hole packaged [8199-77] N. Jiang, H. Luo, W. Liu, National Univ. of Defense Technology (China); C. Sun, Henan Industry Univ. (China); Z. Li, Navy Submarine College (China); H. Yang, Y. Hu, National Univ. of Defense Technology (China)

$81991 \mathrm{G}$ Proper temperature for Cs atomic magnetometer [8199-78]

Q. Liu, Harbin Engineering Univ. (China) and Northeast Petroleum Univ. (China); J. Zhang,

X. Zeng, J. Li, Q. Li, Q. Huang, S. Han, Z. Huang, W. Sun, Harbin Engineering Univ. (China)

$81991 \mathrm{~J} \quad$ Underground fluid composition analysis based on the near infrared spectrum [8199-85]

W. Li, Y. Liao, M. Zhang, Tsinghua Univ. (China)

$81991 \mathrm{~K}$ A fiber-Bragg-grating sensor interrogation system using in-fiber Fabry-Pérot interferometer [8199-91]

T. Wang, Nanjing Normal Univ. (China) and Nanjing Univ. of Information Science \&

Technology (China); M. Wang, Nanjing Normal Univ. (China)

$81991 \mathrm{~L}$ A miniature extrinsic fiber Fabry-Perot pressure sensor based on fiber etching [8199-94]

Y. Ge, J. Zhou, T. Wang, Nanjing Univ. of Information Science \& Technology (China)

$81991 \mathrm{M}$ Polymer optical fiber large strain sensing technology based on bending loss [8199-96]

Q. You, Y. Huang, Y. Lin, Tianjin Univ. (China)

$81991 \mathrm{~N}$ Strain-insensitive optical fiber Mach-Zehnder interferometric temperature sensor [8199-98]

Y. Yu, L. Jiang, S. Wang, J. Yang, B. Li, Beijing Institute of Technology (China)

Author Index 
Downloaded From: https://www.spiedigitallibrary.org/conference-proceedings-of-spie on 26 Apr 2023

Terms of Use: https://www.spiedigitallibrary.org/terms-of-use 


\section{Symposium Committee}

General Chairs

Songlin Zhuang, University of Shanghai for Science and Technology (China)

Brian Culshaw, University of Strathclyde (United Kingdom)

Conference Cochairs

Yuri Chugui, New Siberia Academy of Sciences (Russian Federation)

Arthur Chiou, National Yang-Ming University (Taiwan, China)

Shenghua Ye, Tianjin University (China)

Honorary Chairs

Daheng Wang, Chinese Academy of Sciences (China)

Guoguang Mu, Nankai University (China)

Bingkun Zhou, Tsinghua University (China)

Technical Program Chair

Guofan Jin, Tsinghua University (China)

Technical Program Cochairs

Jinxue Wang, SPIE

Yimo Zhang, Tianjin University (China)

Local Organizing Committee Chair

Youhua Wu, China Instrument and Control Society (China)

Local Organizing Committee Cochairs

Guoqiang Ni, Beijing Institute of Technology (China)

Daoyin Yu, Tianjin University (China)

Yulin Xi, Beijing Hamamatsu Photon Techiques Inc. (China)

General Secretary

Youhua Wu, China Instrument and Control Society (China) 
Administrative Vice General Secretary

Boyu Ding, Beijing Institute of Technology (China)

Vice General Secretaries

Yuejin Zhao, Beijing Institute of Technology (China)

Tiegen Liu, Tianjin University (China)

Qionghui Feng, University of Shanghai for Science and Technology (China)

Cunlin Zhang, Capital Normal University (China)

Local Organizing Committee

Duanyi Xu, Tsinghua University (China)

Weimin Chen, Chongqing University (China)

Hongda Chen, Institute of Semiconductors (China)

Shangzhong Jin, China Jiliang University (China)

Libo Yuan, Harbin Engineering University (China)

Chunqing Gao, Beijing Institute of Technology (China)

Shiqiao Qin, National University of Defense Technology (China)

Tian Lan, Beijing Institute of Technology (China)

Cuiling Li, Beijing Institute of Technology (China)

Liquan Dong, Beijing Institute of Technology (China) 


\title{
Conference Committee
}

\author{
Conference Chairs
}

Brian Culshaw, University of Strathclyde (United Kingdom)

YanBiao Liao, Tsinghua University (China)

Anbo Wang, Virginia Polytechnic Institute and State University (United States)

Xiaoyi Bao, University of Ottawa (Canada)

Xudong Fan, University of Michigan (United States)

Program Committee

Yunjian Rao, University of Electronic Science and Technology of China (China)

Weimin Chen, Chongqing University (China)

Kin Seng Chiang, City University of Hong Kong (Hong Kong, China)

Wei Jin, Hong Kong Polytechnic University (Hong Kong, China)

Libo Yuan, Harbin Engineering University (China)

Zhe Chen, Jinan University (China)

Gan-Ding Peng, University of New South Wales (Australia)

Weihong Bi, Yanshan University (China)

Tingyun Wang, Shanghai University (China)

Claire Gu, University of California at Santa Cruz (United States)

Rongshen Chen, The University of Birmingham (United Kingdom)

Min Li, Wuhan University of Technology (China)

Yuanhong Yang, BeiHang University (China)

Benli Yu, Anhui University (China)

Shibin Jiang, NP Photonics, Inc, (United States)

Hai Xiao, University of Missouri (United States)

Tiegen Liu, Tianjin University (China)

Fajie Duan, Tianjin University (China)

Bo Jia, Fudan University (China)

Xinyong Dong, China Jiliang University (China)

Session Chairs

Session 1

Rongsheng Chen, University of Oxford (United Kingdom)

Min Li, Wuhan University (China)

Session 2

Min Li, Wuhan University (China)

Rongsheng Chen, University of Oxford (United Kingdom) 
Session 3

Yuanhong Yang, BeiHang University (China)

Libo Yuan, Harbin Engineering University (China)

Session 4

Libo Yuan, Harbin Engineering University (China)

Yuanhong Yang, BeiHang University (China)

Session 5

Benli Yu, Anhui University (China)

Xinyong Dong, China Jiliang University (China)

Session 6

Xinyong Dong, China Jiliang University (China)

Benli Yu, Anhui University (China) 


\section{Introduction}

These proceedings are from the 2011 International Conference on Optical Instrument and Technology (OIT2011), held in Beijing, China, 7-9 November 2011. The conference was the third event following the success of OIT'08 and OIT'09 and was sponsored and supported by SPIE, China Instrument and Control Society (CIS), and the Chinese Optical Society (COS).

OlT2011 was a professional conference which was combined and focused on instrument science and related technology, and involved in many technical aspects such as detection; observation; information collection, transfer and storage; communication; economization on energy; environmental protection; inspection and prevention of food security, traffic safety and mine safety; measure and control for aviation and space engineering, etc.

These proceedings, a collection of six volumes, contain the accepted oral and poster papers presented at OIT2011. It is truly a great pleasure for me that the most recent progress in optical instrumentation technology is reported in the OIT2011 proceedings. I firmly believe that the papers included in these volumes will provide reference information in the most up-to-date techniques of optical instrumentation technology.

The OIT2011 conference collected over 330 papers from different countries or regions of the world. Over 300 authors came from more than 12 countries. This conference consists of eight oral sessions (and a one-day poster session): Optical Systems and Modern Optoelectronic Instruments; Optical Device \& Integration; Optical Sensor and Applications; Opto-electronic Imaging and Processing Technology; Optoelectronic Measurement Technology and System; Solid State Lighting and Display Technologies; Holography, Speckle Pattern Interferometry and Application; Micro/Nano Manufacturing and Metrology. Published in these six volumes of the Proceedings of SPIE are close to 330 papers. The technical fields of the presented papers at the conference cover a lot of current advanced technologies. The cutting-edge technologies and applications of optical instruments are discussed. Quite a few invited papers describe exciting achievements in the fields of optical instrument technology. It is evident that the OlT2011 conference has provided an excellent platform for participants and colleagues in research and development to share the technical progress and to develop new partnerships or broaden new markets.

SPIE has given great support to organize this international conference by collaborating with us in the whole organizing process from abstract collection to the proceedings publication. COS has provided great support and assistance. 
Finally, on behalf of CIS and conference general chairs, I would like to heartily thank our supporters and committee members for all they have done for this conference. Thanks also go to all authors for their contributions, to all of the participants and friends for their interest, especially those who have traveled great distances and taken time from their busy schedules to attend the conference. Thanks also go to the staff of CIS for their support. I am also grateful to the SPIE staff for their support and collaboration in publishing these six volumes.

Songlin Zhuang

Chairman, China Instrument and Control Society (CIS) 